\title{
PELA EXISTÊNCIA DE PARADIGMAS PROFISSIONAIS NA LICENCIATURA EM LETRAS
}

\author{
Marcos Gustavo Richter ${ }^{1}$
}

RESUMEN: Este artículo tiene como objetivo abogar por la existência de paradigmas profesionales en capacitación para la educación lingüística. Examinamos, em primer lugar, la necesidad de una teoria para guiar el trabajo experto, presentandose los principales conceptos de la Teoria Holistica de la Actividad pertinentes para la educación lingüística. Em segundo lugar, se discute la formación simple o doble y su importância em el problema. Finalmente, se aboga por um plan de estudios favoreciendo el encuadre de trabajo guiado por paradigmas.

PALABRAS-CLAVE: Teoria Holistica de la Actividad, plan de estudios, paradigmas profesionales

\section{PRIMEIRO PASSO: A ESCOLHA DE UMA TEORIA}

Este artigo visa a contribuir para o debate em torno das reformas curriculares dos cursos de Letras, com destaque às licenciaturas em Letras, com base nos fundamentos teóricos propiciados pela Teoria Holística da Atividade, doravante THA (RICHTER, 2008, 2011). Num primeiro momento, consideramos oportuno chamar a atenção para o status da THA no campo metateórico das Teorias da Atividade e na esfera da formação inicial e continuada do profissional de Letras.

Com a fundação da Linguística por Saussure, passou a circular incontroversamente no meio acadêmico da área o axioma de que, na ciência, o ponto de vista cria o objeto. Mas, a nosso ver, há algo axiomático importante a acrescentar: o problema cria a teoria.

Passemos a explicar: se considerarmos a ciência como uma sucessão de modelos de um tipo especial (para distingui-los dos modelos do senso comum, da filosofia, da religião etc.), sem dúvida esses modelos tenderão a com-

\footnotetext{
${ }^{1}$ Professor Titular Pós-Doutor do Departamento de Letras Vernáculas do Centro de Artes e Letras da Universidade Federal de Santa Maria-RS. E-mail: richtermg@gmail.com.
} 
partilhar de determinadas propriedades — mas a verdade ou falsidade do construto teórico não é uma delas.

Uma teoria não é melhor ou pior que outra em função de um suposto ranking de "veracidade" que cada uma viesse a ter. Então, cabe perguntar: em que sentido fundamental podemos comparar teorias para decidir por uma delas? Eis a resposta: por sua maior ou menos utilidade (ou talvez uma solene constatação de inutilidade). Ou seja, pelo potencial do modelo em gerar proposições relevantes que possam ser empiricamente confirmadas, refutadas ou ao menos postas em dúvida pela comunidade científica. E neste ponto permitamme destacar uma palavra-chave na sentença anterior: relevantes.

Uma teoria científica pode ter maior ou menor criatividade metafórica, maior ou menor simplicidade, maior ou menor grau de abstração, maior ou menor poder explicativo. Mas ao pesquisador interessa formular perguntas (quer "puras", quer aplicadas), tentar buscar respostas apropriadas e, em função disso, selecionar o conjunto de suposições em que o problema, por sua natureza, melhor se situe e equacione - em outras palavras, o construto convencional em que seu problema faça mais sentido.

E aí chegamos ao nosso axioma: uma teoria é (mais ou menos) útil em função do que o pesquisador considera relevante explorar, descrever ou explicar. Por exemplo: o behaviorismo não é mais ou menos "verdadeiro" em si mesmo do que sua teoria opositora, o inatismo, se considerarmos que vão ao encontro, respectivamente, de quem considera relevantes na linguagem seus aspectos de adaptação ambiental e de quem nela privilegia um princípio genético subjacente a todo idioma.

\section{UMA TEORIA DA PROFISSIONALIZAÇÃO}

A THA compartilha uns poucos pressupostos básicos com as demais versões da Teoria da Atividade. Não sendo nossa pretensão alongar a discussão sobre aproximações e distanciamentos teóricos nesse campo, apenas mencionaremos pontos de alinhamento dignos de nota, a saber:

a) O ser humano constitui-se e desenvolve-se como tal agindo sobre o mundo e transformando-o de acordo com suas necessidades. Nesse 
sentido, é inseparável de seu ambiente e de seu tempo: é um ser histórico e contextualizado.

b) Age no mundo em grupos organizados e de forma mediada por artefatos corpóreos e incorpóreos de sua própria criação e constante aperfeiçoamento. Nesse sentido, é inseparável de práticas sociais instrumentalizadas e regradas: é um ser social e cultural.

c) Os artefatos que emprega abrangem objetos materiais dotados de instrumentalidade, constituidores e direcionadores da psicomotricidade humana intencional, e signos de complexidade muito variada, constituidores e tipificadores da cognição e suas manifestações comportamentais. Destes, merecem destaque os sistemas de signos (linguagens), as instituições e os papéis sociais. Nesse sentido, o ser humano é um ser cuja cognição e comunicação são (re)construídos e operantes sistemicamente.

Entretanto, a THA separa-se em maior ou menor grau das versões de descendência vygotskiana precisamente pelo tipo de problema que privilegia. A maioria destas últimas tende a centralizar as questões em torno da oposição exterioridade/interioridade (do ser humano), conferindo a elas um viés predominantemente molecular (que se mostra mais evidente nas especulações sociocognitivas).

Uma nota dissonante pode ser encontrada na versão da escola finlandesa da TA. Sua obra seminal Learning by Expanding (ENGESTRÖM, 1987) parece enfatizar a concepção de cultura como processo e criação. Porém, a partir do momento em que amplia o conceito de Zona de Desenvolvimento Proximal para a esfera institucional, deixa entrever (nos trabalhos de aplicação isso fica claro) questionamentos de natureza institucional (via regras e divisão de trabaIho). A problemática central, para o autor, é tentar entender como as práticas sociais podem ser ao mesmo tempo bem administradas (centralizadamente) e caminhar para soluções satisfatórias de seus problemas por meio de mudanças e criatividade predominantemente molares.

O percurso sui generis da THA como modelo teórico (e heurístico) advém fundamentalmente de duas preocupações nossas que, a nosso ver, não poderiam ter lugar no campo vigotskiano assim como hoje se apresenta. São elas: a acrasia - o descompasso entre o que o profissional ou o trainee dizem 
sobre sua prática e o que efetivamente fazem - e a (necessidade de) emancipação profissional - a (constatada) sujeição do profissional a ingerências exógenas a seu grupo laboral, descaracterizadoras, causadoras de distorções e comprometedoras da qualidade do trabalho especializado atribuído a esse grupo.

As mudanças mais importantes da THA em relação às demais versões da TA residem nos seguintes aspectos:

a) A noção de sujeito adquire status discursivo e, em seu lugar, no esquema piramidal engestromiano, entra a de papel (profissional) como conjunto de regularidades sistêmicas.

b) A noção de comunidade, abrangente demais (e indicadora da concepção de sistema aberto), é substituída pela noção conjunta de grupo de referência (por identificação) e grupo de pertença (por atribuição), compatíveis com a de papel social - noção esta, por sua vez, central em uma concepção de sistema fechado.

c) O conceito subjacente de sistema (ou de sistemicidade) passa de aberto (abertura cognitiva e operacional) a fechado (abertura cognitiva e clausura operacional). Acompanha esta mudança a noção opositiva de autopoiese/alopoiese sistêmica (determinação endógena vs. exógena das operações de produção de sentido em sistemas sociais).

d) A noção de instrumentalidade é notavelmente ampliada, de modo a praticamente abranger a semiosfera humana. A antropossemiose instrumentaliza todas as atividades humanas, porém, mais do que isso, constitui o ser humano tanto na dimensão externa (cultura, instituições, sociedade, história) quanto na interna (processos psicológicos conscientes e inconscientes). Diante disso, fenômenos semiolinguísticos como formações ou lugares discursivos, formações ideológicas, metáforas teóricas ou arquetípicas adquirem status de instrumentos para as operações de produção de sentido - operações genuinamente sistêmicas na THA, autopoiéticas ou alopoiéticas, comunicativas (operações $\Sigma$ ) ou cognitivas (operações $\Psi$ ).

e) O conceito de divisão de trabalho, que na perspectiva da versão engestromiana serve a propósitos organizacionais centralizadores, na THA transmuta-se no de organização funcional, que difere do anterior por pa- 
rametrizar não indivíduos-sujeitos, mas papéis profissionais (funcionalmente definidos), que preexistem aos indivíduos-sujeitos e, de certo modo, independem destes. Claro que, assim como língua não pode subsistir sem fala, papéis profissionais não podem subsistir sem indivíduossujeitos que os internalizem e exerçam. $O$ resultado dessa mudança é a abertura epistêmica (antes não existente) para a problemática da autonomia dos grupos laborais - ou seja, de sua emancipação, autogestão, autopromoção e autorregulação.

f) A palavra-chave que ajuda a distinguir a THA das demais TAs - e que Ihe confere o potencial para problematizar a diferenciação, autonomia e autorregulação de atividades especializadas como sistemas sociais - é autopoiese. Este, diga-se de passagem, é o mesmo conceito central que encontramos na Teoria dos Sistemas Sociais de Niklas Luhmann (1995, 2011; VILLAS-BOAS Fo, 2006). ${ }^{2}$ Sem falar em autopoiese não se pode falar em sistemas sociais dotados de clausura operacional. Mais ainda, é a premissa da autopoiese que viabiliza a realização de um importante "salto epistêmico" da THA — postular para sistemas sociais (baseados no conceito de papel social) a instrumentalidade de todos os signos (e complexos sígnicos) dotados de função antropossemiótica capaz de efetuar operações de produção de sentido organizadas para gerar assimetria crescente. Sistemas não se reduzem a uma mera diferenciação semiotopológica, mas também determinam dialeticamente o que lhes é entorno, do qual podem extrair e reduzir complexidade para seu desenvolvimento e autogeração. Este movimento autônomo de autodiferenciação de papéis profissionais com suas atividades específicas é um requisito fundamental da autopoiese sistêmica e, até onde sabemos, não faz parte do construto teórico de nenhuma outra versão da TA já proposta.

\section{A THA E A CONSTITUIÇÃO DO PROFISSIONAL DE LETRAS}

\footnotetext{
2 O sociólogo alemão Niklas Luhmann (1926-1997), ao lado do semioticista americano Charles Sanders Peirce (1839-1914) e do antropólogo e ciberneticista inglês Gregory Bateson (19041980) é um dos três autores-raízes da Teoria Holística da Atividade. Vygotsky, Leontiev e Engeström representam influências de fundo.
} 
O profissional de Letras no sentido autopoiético do termo ainda não existe. É uma aspiração dos que defendem sua emancipação jurídica na forma de autarquia (Conselhos Federal e Regionais). Para tanto, será preciso, segundo a Constituição Federal, apresentar um projeto de lei à Câmara dos Deputados, que necessita da adesão (por assinatura) de um número mínimo de cidadãos de ao menos cinco Estados para que possa ser protocolado e tramitar até a esperada aprovação do Poder Legislativo e sanção presidencial.

Enquanto a regulamentação do profissional de Letras, com as terminalidades de bacharéis e licenciados, ainda é um sonho, torna-se viável trabalhar nas bases, fortalecendo-as no empenho de construir sua imprescindível coesão e índole corporativa. Esta iniciativa mobilizadora desdobra-se em duas frentes de organização funcional:

a) A criação de associações de profissionais da área ${ }^{3}$. Desta frente não nos ocuparemos neste artigo.

b) A integração profissional via formação inicial e continuada - que será de agora em diante o recorte aqui discutido.

A concepção de integração profissional da THA envolve princípios autopoiéticos de formação de recursos humanos: sistemas $\Sigma$ autorregulados tornam-se autosseletivos quanto aos sistemas $\psi$ com os quais estabelecem a interpenetração operativa para as práticas articulativas (operações intersistêmicas) e exercitivas (operações de satisfação de uma necessidade social). Essa autosseletividade manifesta-se claramente nas práticas constitutivas pela construção e incorporação, pelo indivíduo inicialmente leigo, de seu papel social por meios de mecanismos de identificação e internalização progressiva.

Esse mecanismo de identificação com o grupo de referência (mais adiante, também grupo de pertença) e internalização progressiva do respectivo papel profissional tem lugar, em nossas práticas sociais acadêmicas, no currículo legitimado pelos órgãos estatais e, em contextos autopoiéticos, pelos próprios profissionais através de seus órgãos de administração descentralizada. A THA denomina o processo de formação integrativa em sistemas alopoiéticos de desenvolvimento profissional corresponsável (DPC), envolvendo três vértices

\footnotetext{
${ }^{3}$ Cabe ressaltar que não estamos nos referindo às associações de pós-graduação, que congregam somente uma parcela do contingente do sistema e, em sistemas alopoiéticos, separam-se dos profissionais do mercado em subcomunidades de prática quase estranhas entre si.
} 
idealmente em regime de cooperação e lealdade ${ }^{4}$ : academia, escola (mercado) e estágio. Temos a convicção de que um currículo de Letras, haja vista o profissional não regulamentado que lança no mercado de trabalho, necessita de um Projeto Político-Pedagógico que preveja as condições necessárias para o DPC.

\section{LICENCIATURA SIMPLES OU DUPLA: FATOR DECISIVO?}

Um dos primeiros aspectos postos em discussão quando se busca a qualidade da formação em Letras, mais precisamente da licenciatura, é a habilitação simples ou dupla do egresso. Seria esta uma questão central? Partiremos deste debate com o objetivo de demonstrar que o elemento decisivo no DPC não é este, e sim outro: a existência de paradigmas em um currículo com integração de áreas. E justificaremos conceitualmente à luz da THA.

Nosso percurso começa com um caso concreto, de onde derivaremos nossas proposições: o curso de Letras da UFSM e sua reformulação curricular hoje em andamento. A escolha não é fortuita: o autor integra o Núcleo Docente Estruturante do curso de Letras e é deste lugar que prossegue com a palavra.

$\mathrm{Na}$ história do curso de Letras da UFSM, desde sua fundação no início dos anos 60 até o final dos anos 90, as licenciaturas eram duplas - com exclusão das letras vernáculas - e até então a única controvérsia estava no oferecimento de licenciaturas curtas ou plenas - ou ambas.

Essa trajetória sofre um ponto de inflexão em 1997, quando é criado um Fórum para debater a implementação das licenciaturas únicas na instituição.

$\mathrm{Na}$ apresentação do PPP do curso de Letras - Inglês e Literaturas de Língua Inglesa estão elencados os principais argumentos em favor dessa mudança. Resumidamente, os pontos levantados eram:

a. A necessidade de atualização do currículo, no empenho de favorecer uma melhor inserção do aluno na nova conjuntura;

b. A necessidade de permitir ao aluno maior aprofundamento dos conhecimentos dos tópicos estudados;

\footnotetext{
${ }^{4}$ Em sistemas laborais autopoiéticos, a cooperação e lealdade entre academia, mercado e estágio é assegurada pelo Código de Ética Profissional, que os Conselhos, por atribuição, fiscalizam.
} 
c. A viabilização da oferta de disciplinas em um único turno, deixando o outro para atividades complementares;

d. A então constatação de que os egressos optam por apenas uma das habilitações ao ingressarem na pós-graduação.

e. A importância de adequar a formação do aluno às exigências de capacitação específicano mercado de trabalho.

Em meados da primeira década deste século, a licenciatura simples foi aprovada, passando a ser a realidade dos cursos de Letras da UFSM. E outra década transcorreu para que se constatasse que as expectativas da ocasião sobre essa mudança pouco se concretizaram. Vamos a um balanço sucinto delas.

O ponto (a), considerado retrospectivamente, atesta uma talvez natural estreiteza de visão na época. Afinal, passávamos para a era digital sem ter a noção das repercussões qure isso acarretaria. A internet mal estava engatinhando. As atuais políticas de inclusão ainda não haviam irrompido com toda a sua pujança. Hoje a libras é componente obrigatório da formação do novo licenciado. E por fim as novas tecnologias avançaram a tal ponto que o ensino não apenas de línguas - tem a respeito muitas perguntas e bem poucas respostas na densa floresta do debate.

Quanto ao ponto (b), nota-se uma contradição entre este e o que o PPP citado defende na seção "finalidades": formar um egresso alicerçado em competências e não mais em meros conhecimentos. Além disso, depoimentos coIhidos dentre alunos e egressos corroboram a queixa de que teorias têm sido (na atual licenciatura simples) providas generosamente, mas com pouca ou nenhuma articulação com as práticas docentes (estágio e realidade escolar do mercado de trabalho), sugerindo que a balança ainda pende para o prato da teoria pela teoria - justamente o desafio que, na sua primeira seção, o referido PPP alegava, na época, ter condições de superar.

O ponto (c) destoa dos demais por manter-se como pauta relevante. Um exame atento revela que o fato puro e simples de a licenciatura ser simples ou dupla não determina a adequação da distribuição da carga horária do curso. Trata-se mais de uma questão de implementação e gerenciamento dotada de bom-senso. 
Por fim, o ponto (d) deixou a desejar, entre outros motivos, a partir do momento em que - de maneira análoga à do item (b) - confundiu conhecimento específico e formação específica. Assinalemos que não são o mesmo: conhecimentos específicos podem ser atinentes às competências específicas, ou não. O conhecimento declarativo pode estar dando sustentação a saberes procedimentais, ou não. Neste último caso, é discutível se seu aprofundamento contribui para um profissional melhor, isto é, se o deixa mais preparado para proceder às funções situadas dentro de seu âmbito profissional.

E na verdade são as competências profissionais os fatores decisivos e o principal objetivo da formação inicial - e de um projeto curricular voltado a um perfil de egresso capaz de bem desempenhar as atribuições específicas de sua esfera de atuação, definidas claramente nos termos de terminalidades e ênfases. Com efeito, sem o senso de terminalidades - que funções o profissional deve estar preparado para desempenhar quando habilitado, em que contextos e em que condições - não há critérios sólidos e consistentes para estabelecer que "conhecimentos específicos", não obstante aprofundados, se impõem como relevantes, decisivos.

Em um artigo de 2005, Paiva se posiciona contra a licenciatura dupla, alegando que tende a formar profissionais - no dizer dela - mal preparados. $A$ autora escreve (PAIVA, 2005, p. 355):

Os projetos pedagógicos em vigor nas licenciaturas duplas continuam privilegiando os conteúdos em língua portuguesa, ficando a língua estrangeira com pouquíssimo espaço na grade curricular. As literaturas, espaço essencial para que o aprendiz tenha input autêntico, experiência estética e imersão na outra cultura, ficam relegadas, geralmente, a duas disciplinas de 30 ou 60 horas. Conteúdos de formação do professor de língua estrangeira são, geralmente, ignorados, e é raro o curso que oferece atividades curriculares que estimulem reflexões sobre aquisição, ensino e aprendizagem de língua estrangeira.

Sem dúvida, essas são preocupações importantes para a organização de um currículo de letras-licenciaturas, quando se pensa em qualidade na formação do professor de línguas. Entretanto, procuraremos argumentar na direção de que o fator decisivo para obtê-la não reside meramente no modelo simples ou duplo de licenciatura em si mesmo. E sim em uma série de fatores entrelaçados, capazes de determinar a diferença concreta entre currículo centrado na excelência do conhecimento e currículo centrado na excelência da 
competência profissional. Falamos de um conjunto articulado de disciplinas e atividades complementares que prioritariamente forma ( centralizado no saberfazer), por oposição ao seu correlato que prioritariamente informa (centrado no saber-sobre).

Examinemos os três pontos destacados pela autora, um a um, começando pelo último: Conteúdos de formação do professor de língua estrangeira são, geralmente, ignorados, e é raro o curso que oferece atividades curriculares que estimulem reflexões sobre aquisição, ensino e aprendizagem de língua estrangeira. O NDE do Curso de Letras da UFSM realizou um levantamento da opinião de acadêmicos, formandos, egressos e docentes dos cursos de Português, Inglês e Espanhol ao longo de um ano.

Entre as tendências reivindicatórias colhidas sobre as grades curriculares das licenciaturas propriamentes ditas, merecem destaque as seguintes, relativas às disciplinas obrigatórias:

- realinhamento das disciplinas ao objetivo geral da formação de professores;

- entrosamento entre disciplinas específicas de Letras e disciplinas pedagógicas;

- entrosamento entre disciplinas da grade (com destaque às de literatura) e práticas de ensino;

Isso significa que a crítica geral apresentada por Paiva sobre as licenciaturas duplas - ao menos no nosso contexto - se mantém ou se repete para as licenciaturas simples. A inferência autorizada pelos referidos depoimentos é que o mero fato de as licenciaturas em Letras serem simples ou duplas em si mesmo não parece influir visivelmente na qualidade de ensino quando o objetivo posto é - para novamente empregar os mesmos termos de Paiva - a formação docente. A esse respeito, a autora comenta em outro trecho (PAIVA, idem, p.353): Apesar de a grande maioria dos cursos serem de licenciatura, a vocação do corpo docente da área de Letras continua muito voltada para um perfil de bacharelado, pois poucos são os docentes interessados em questões de ensino-aprendizagem.

Em outras palavras, a vocação (ou distorção?) bacharelesca é um sério risco enfrentado pelas licenciaturas em Letras, quer simples, quer duplas. A 
questão central de melhoria da formação parece, então, residir em outros aspectos, como procuraremos deixar claro mais adiante.

A próxima questão incide sobre o lugar das licenciaturas de língua estrangeira no curso: As literaturas, espaço essencial para que o aprendiz tenha input autêntico, experiência estética e imersão na outra cultura, ficam relegadas, geralmente, a duas disciplinas de 30 ou 60 horas. A nosso ver, essa crítica merece um ligeiro realinhamento. Sem dúvida, a carga horária das literaturas de língua estrangeira deve obedecer a um mínimo para que os gêneros literários possam ser suficientemente trabalhados. Mas o problema não se esgota nisso. Como pudemos ver acima, a atitude acadêmica beletrista anda à espreita, e o ensino da literatura é o setor do currículo tradicionalmente mais vulnerável ao enfoque bacharelesco. Neste aninham-se preferencialmente teorias que,por mais férteis em debates e reflexões que possam ser, não só estão longe de serem autoaplicáveis ao desenvolvimento do aluno-leitor, como também deixam de apontar caminhos para a didática fora de um contexto curricular integrador que lhes dê suporte.

Como se não bastasse, a literatura de língua estrangeira tem uma função escolar algo diversa da sua correlata de língua materna. Enquanto a segunda contribui para expandir e redefinir valores e visões de mundo, a primeira - embora se constitua incontroversamente em input autêntico, experiência estética e imersão (inter)cultural - compartilha estas últimas prerrogativas com outros gêneros textuais considerados "menos nobres" na perspectiva beletrista, como o humor, a publicidade, os quadrinhos etc.

Ou seja, o encaminhamento dado a essa questão nos leva a dar destaque à concepção de linguagem como prática social e ao papel fundamental, na organização e tipificação das atividades sócio-histórico-culturais, dos gêneros textuais - os quais, diga-se de passagem, podem ser trabalhados com a finalidade de desenvolver habilidades e competências comunicativas, dessa forma afastando-se, em boa parte, das amarras da tradição beletrista.

Falta comentarmos a terceira questão levantada por Paiva: Os projetos pedagógicos em vigor nas licenciaturas duplas continuam privilegiando os conteúdos em língua portuguesa, ficando a língua estrangeira com pouquíssimo espaço na grade curricular. A esse respeito, o que sugerem os depoimentos recentemente colhidos pelo NDE para a avaliação dos currículos das licenciatu- 
ras simples em vigor? Curiosamente, oposto. Depoimentos de acadêmicos das habilitações em língua estrangeira lamentam a pouca base em língua materna que trazem ao ingressar no curso - trazem e carregam, pois assinalam que isso afeta inclusive a preparação para atuarem mais tarde no mercado de trabaIho.

Ao mesmo tempo, os alunos reivindicam um período inicial de nivelamento - que pode ser aplicado à base tanto em língua materna quanto em estrangeira. Esta questão vem ao encontro de uma antiga constatação segundo a qual alguns acadêmicos imaginam-se passando por um curso de línguas, e não uma preparação profissional para ministrá-las.

Logo, entendemos que esta última questão da autora merece, como encaminhamento, que se pense em um currículo que inclua uma fase inicial denominada de núcleo comum, no primeiro ano - de fundamentação e nivelamento, preparando leitores e produtores de texto (em língua materna e estrangeira, em gêneros não literários e literários) competentes e capazes de obter o devido aproveitamento das posteriores disciplinas de formação teórica e metodológica em língua e literatura para sua capacitação docente. Esta primeira etapa, então, está centrada no domínio de objeto (saberes procedurais do próprio profissional e suas correspondências metacognitivas) ao longo de dois semestres e convém que inclua algumas disciplinas de caráter introdutório, das áreas de Letras e de Educação, oferecendo ao estudante uma visão panorâmica de sua profissão e já procedendo à imersão gradual dele na prática escolar da área.

A segunda fase se concentraria no domínio de conhecimento teórico e metodológico. Ela incluiria, ao longo de quatro semestres, disciplinas de caráter teórico-metodológico abordando plenamente as teorias, os conceitos e as aplicações que anteriormente haviam recebido somente menção panorâmica. Essas disciplinas seriam distribuídas segundo uma lógica de complexidade crescente e interface transversal. O objetivo, agora, é construir o conhecimento especializado capaz de alicerçar suas tomadas de decisão no contexto didático. Prossegue a imersão gradual do acadêmico no contexto escolar e a esta altura ele passa a ser um colaborador dos docentes do ensino básico, realizando de forma supervisionada tarefas profissionais de retaguarda, como correção de produções textuais com fins de diagnóstico e controle de eficácia metodológica, 
criação de bancos de textos de diversos gêneros e organização destes por riqueza relativa de propriedades formais e discursivas, entre outras. Nesta etapa, prevê-se que o aluno já aprenda gradativamente a trabalhar (profissionalmente) em equipe, dividindo e integrando tarefas com harmonização de esforços e consenso teórico e metodológico.

Por fim, a terceira fase alicerçaria o dominio de competências profissionais. Ela ocuparia os dois últimos semestres, pondo estudante diante de turmas já como trainee. Ou seja, como uma espécie de profissional júnior capaz de - sempre sob supervisão de um profissional sênior (ou mais) - tomar decisões no tocante a todas as fases de intervenção especializada, quais sejam, estipulação de objetivos e prioridades, seleção e escalonamento de procedimentos e recursos, implementação destes com observação e feedback de resultados, ajustes posteriores e constantes (o que, como já mencionamos, poderia e mesmo deveria ser um trabalho de equipe, tipo multiespecialidades). Além disso, este neófito agora estaria apto a escolher uma ênfase (ou mais), que pode especializá-lo em: a) gerenciamento de turmas (atendimento didático grupal e personalizado); b) design de cursos, aulas e atividades; c) avaliação (diagnóstica, de controle e seletiva).

\section{DA ACRASIA AO ENQUADRAMENTO NA LICENCIATURA EM LETRAS}

Se acompanharmos atentamente os três últimos parágrafos da seção anterior, veremos que cada um dos "degraus" do currículo não apenas procede à imersão gradual do estudante nas práticas escolares, mas também o coloca gradualmente em contato com os outros dois recursos humanos chave do DPC. Temos aí os três vértices do tripé: estudante, profissional do ensino básico, profissional da academia.

Alguém poderia dizer: mas isso simplesmente retoma uma preocupação nada nova, que é fazer extensionismo aproximando universidade e escola em iniciativas de formação inicial e continuada. Alguns talvez acrescentassem: os projetos criados com essa perspectiva propiciariam as oportunidades para a semeadura do tão propalado "professor reflexivo".

Mas será que estaríamos ingenuamente reinventando a roda? Nesta seção demonstraremos que não. E, precisamente para evitar o indesejável ris- 
co de repetir velhas práticas e mentalidades em formação docente, a THA distancia-se das demais Teorias da Atividade. Peço, então, que o leitor me acompanhe atentamente nas considerações que seguem.

Partiremos da palavra-chave posta acima entre aspas: professor reflexivo. O que muitos anos de prática em formação docente vêm nos evidenciando empiricamente a respeito das assim-chamadas práticas reflexivas? Resposta: a acrasia, que consiste na dissociação entre discurso (com seus conceitos e valores) e prática, entre o dizer e o fazer (cf. STRACK e DEUTSCH, 2004). Na perspectiva da THA, o principal obstáculo na formação inicial e continuada pensando-se nos profissionais do mercado, ou seja, licenciados atuando como educadores linguísticos - é a adoção por estes de um discurso alinhado ao dos formadores (ou seja, falar aquilo que os formadores querem ouvir), paralelamente à insistência em condutas didáticas retrógradas, nocivas e conceitualmente distantes daquilo que esses docentes alegam adotar, ao participarem de iniciativas extensionistas. Em suma, trata-se, não de genuína reflexividade, mas precisamente de sua dissimulação. Mantida desse modo uma zona de conforto laboral, a realidade da nossa educação linguística (e também de outras) porfia em sua toxicidade, como a compulsão à repetição no campo freudiano.

Como enfrentar o problema da acrasia? Aqui esboçaremos apenas alguns caminhos, sem pretender enveredar por uma discussão exaustiva. Para começar, esse é um problema dificilmente constatável em sistemas profissionais autopoiéticos. Por exemplo, um médico que se apresenta homeopata pratica efetivamente uma medicina homeopática. Não vemos um psicólogo se rotular cognitivo-comportamental e praticar no consultório uma clínica rogeriana. Já o profissional de Letras (cujo sistema social é francamente alopoiético) padece de uma inquietante falta de demarcação de seu território interventivo e, quando licenciado, tem dificuldade em identificar e articular sua abordagem de base: é um educador linguístico behaviorista? inatista? interacionista?

Mas, prossigamos. Entre as diversas propriedades que distinguem sistemas sociais autopoiéticos dos alopoiéticos, queremos destacar uma: a consistência das operações internas diante do entorno. Isso significa que sistemas autopoiéticos enfrentam a hipercomplexidade de fenômenos externos com maior poder redutor e auto-organizador. Isso se deve principalmente ao fato de 
serem dotados de estruturas e algoritmos que são fortemente refratários aos fatos não pertinentes e diretivos para os fatos pertinentes. Os sujeitos que assumem um papel autopoiético realizam observações de $1^{\circ}$ e $2^{\circ}$ graus internas e externas ao sistema (= coordenações de intervenções e coordenações de coordenações de intervenções) em condições de interpenetração (= interface operacional $\Psi / \Sigma$ ) regidas por expectativas normativas. Em contraste, as condições em que sujeitos no desempenho de papéis alopoiéticos o fazem são regidas por expectativas cognitivas (LUHMANN, 1983).

Afirmar que papéis profissionais em sistemas autopoiéticos operam em condições de normatividade equivale, de certo modo, a dizer que suas observações e intervenções ocorrem em campos teóricos unificados, não conflitantes. Hall, Lindzey \& Campbell (2000) explicam isso de forma particularmente feliz, quando afirmam que uma das funções da teoria é evitar a dispersividade observacional diante da complexidade dos fenômenos. Expectativas normativas sinalizam ao observador para que leve em consideração somente determinada parte dos aspectos do evento-objeto de intervenção, ignorando as demais. Expectativas cognitivas são dotadas de baixo ou muito baixo poder redutor de complexidade, e o observador nessas condições se depara com inúmeros modos diferentes de perspectivar, analisar e, ao final, de intervir no objeto. Diante disso, nada tem de espantoso que $\underline{n}$ observadores em situação de alopoiese se posicionem em $\underline{n}$ ângulos do mesmo evento empírico, e em decorrência façam n observações bem diferentes. Cada um procede de determinado modo, ninguém se entende, nenhuma comunidade de práticas consegue se formar. E se alguém entra com alguma pretensão de "reflexividade", afloram fragilidades psicológicas (pois a interpenetração $\Psi / \sum$ não é subjetiva, e sim sistêmica!), e entra em cena a acrasia como uma das várias defesas dos sujeitos.

A esse respeito, é oportuna a leitura deste trecho dos autores citados (idem, ibidem, p. 35-36):

A teoria permite que o observador abstraia a partir da complexidade natural de uma maneira sistemática e eficiente. As pessoas abstraem e simplificam quer usem ou não uma teoria. No entanto, se não seguirmos a orientação de uma teoria explícita, os princípios que determinam a nossa visão ficarão escondidos em suposições implícitas e em atitudes das quais não estamos conscientes. A teoria especifica para o usuário um número limitado de di- 
mensões, variáveis ou parâmetros mais ou menos definidos e de importância crucial. Os outros aspectos da situação podem em certa extensão ser ignorados do ponto de vista desse problema. Uma teoria útil vai detalhar instruções explícitas sobre os tipos de dados que devem ser coletados em relação a determinado problema. (grifos nossos)

Ora, a THA compartilha do mesmo ponto de vista, principalmente quanto aos trechos em destaque. Somente podemos combater a acrasia, a fragmentariedade identitária e a dispersividade das práticas fortalecendo as expectativas normativas do papel profissional já em suas bases - e de forma a também superar o abismo existente entre profissionais da academia e do mercado ${ }^{5}$. Ou seja, em uma ocupação desprovida de consistência teórico-metodológica, como se depreende da argumentação acima, o "profissional reflexivo" consegue ir pouco além da "associação livre" típica dos divãs. O DPC acoplado a um currículo com senso de terminalidades responsivo ao mercado e que construa e fortaleça um perfil de egresso competente no exercício de suas atribuições está, sem dúvida, entre as iniciativas prioritárias.

Como opera sistemicamente o DPC? Não basta que universidade, estágio e escola se aproximem. Se isso não for acompanhado da consolidação (num primeiro momento, molecular) de expectativas normativas, repetiremos a síndrome do professor reflexivo-acrásico. Será preciso ainda uma inversão. Geralmente as iniciativas de aproximação universidade-escola têm se pautado por autores fiéis à Escola de Frankfurt, que partem da premissa de que a reflexão sistemática (o trabalho com a cognição) leva à modificação da ação. Não é o que temos observado, e a THA defende a premissa inversa: a ação sistemática (ou melhor, a ação modelar sistemática) leva à modificação da cognição.

Curiosamente, a Escola de Frankfurt se apresenta como uma das herdeiras não tão próximas do velho marxismo. Mas precisamente o velho Marx já alertava sobre o risco da ineficácia de se tentar modificar o mundo através de um reiterado jogo de interpretações. Foi exatamente essa tese que o levou a atacar abertamente os assim-chamados "ideólogos", os pensadores autoconsi-

\footnotetext{
${ }^{5}$ Esse abismo praticamente inexiste nas profissões autopoiéticas. A docência em terceiro grau é somente uma das atribuições possíveis do profissional habilitado e inscrito no Conselho, e os indivíduos integrantes desse sistema posicionam essa atribuição praticamente no mesmo patamar que as demais. Não há "estabelecidos e outsiders" (confrontação academia vs. Mercado - os termos são tomados de ELIAS, 2000); ao contrário, todos são colegas e, nessa saudável mutualidade, privam da mesma dignidade e prestígio.
} 
derados ativistas políticos que acreditavam poder mudar o mundo simplesmente "pensando ideias contestatórias".

O leitor poderia a esta altura indagar: mas como fica o extensionismo que não cai nessa flagrante ingenuidade e procura partir da prática e pensar a prática? Resposta: não é o ponto de partida da reflexão o fator decisivo. Por quê? Porque em ambos os casos a cognição é distorcida justamente pela natureza das operações alopoiéticas de que participa, desprovidas da base teóricometodológica comum a uma comunidade de práticas. E com apenas uma diferença: a distorção dos ideólogos seria uma distorção de $2^{\circ}$ grau (= operações sistêmicas consistindo em observações de observações), e a distorção do "pensar a prática", de 1ำ grau (= operações sistêmicas consistindo em observações de fenômeno). E, para agravar a situação, pensar a prática sem o alicerce de expectativas normativas é cair num círculo vicioso: parte-se de uma prática fragmentária e dispersa, e as operações tanto cognitivas quanto comunicativas não dão conta de reduzir essa complexidade. Circularidade, compulsão à repetição, pedra de Sísifo, deem o nome que quiserem, o caminho a percorrer é o inverso: adoção voluntária e insistente, pelos componentes do tripé universidade / estágio / escola, de um conjunto consistente de práticas integradas. A THA dá a isso o nome de enquadramento, e dele trataremos com mais detalhes na próxima e última seção.

\section{CONSIDERAÇÕES FINAIS: ENQUADRAMENTO E PARADIGMA}

As profissões regulamentadas têm muito a ensinar às que ainda permanecem num "limbo" social apesar de incontroversamente importantes pelo papel exercido, como é o caso dos profissionais de Letras. Eis um desses preceitos tácitos: a construção do conhecimento fundador de práticas institucionalizadas é inseparável da construção de um lugar social (sistema) compatível. (RICHTER, 2011, 111).

Esse rebaixamento no ranking de profissões acompanha-se não só por uma demanda sensivelmente menor, mas também por uma força identificatória bem menos atuante. O irônico nessa situação é que precisamente uma condição sine qua non para o DPC reside na identificação do ingresso e do egresso com a educação linguística. Sem isso, não há o desejo do estudante e mesmo 
do formado em internalizar esse papel profissional, dele apropriar-se por meio da adoção voluntária das formas de conduta correspondentes ao modelo do respectivo grupo de referência.

Aguirre, apud Richter (2011) adverte, a respeito:

\begin{abstract}
...o desempenho de uma função passa antes pelo conhecimento, compreensão e aceitação do respectivo papel social (profissional, no caso) - condições para poder assumi-lo. Isso significa que o aluno deve pautar o roteiro de sua formação por um grupo organizado (o qual, com seus valores, atitudes, práticas, referências conceituais, aspirações, concretiza, num tempo e lugar, determinado papel) que lhe sirva de referência e alvo de investimento afetivo (isto é, que the ancore identificação) (grifo do autor).
\end{abstract}

Uma vez que esteja criada uma triangulação universidade / estágio / escola coligada pela identificação sólida dos participantes com um modelo de profissional em comum, o próximo passo será pautar as ações distribuídas entre os participantes por um conjunto consistente de operações sistêmicas normatizantes. Estas farão com que o trabalho especializado seja realizado e coordenado à luz de uma progressiva diferenciação entre fenômenos protossistêmicos (perturbações do sistema) e fenômenos sistêmicos - o que necessita, como vimos, de um referencial teórico comum, embasador de ações, prioridades e definições empíricas. Para isso, é necessário o enquadramento de trabalho.

Assim, entendemos por enquadramento a paradigmação e parametrização dos três metafatores da atividade, quais sejam: atribuição, mediação e controle. Cada um desses metafatores ordena as operações (de $1^{\circ}$ e $2^{\circ} \mathrm{grau}$ ) em cascata do objeto da atividade (foco empírico) para os procedimentos situados e por fim aos seus fundamentos conceituais. Assim, a atribuição dispõe sobre 0 bem social confiado ao papel laboral, às condutas orientadas a essa finalidade e os fundamentos gnoseológicos e praxeológicos dessa conduta. A mediação, sobre os recursos a utilizar, os procedimentos para intervir e os construtos teóricos orientadores das respectivas tomadas de decisão. E o controle, sobre a finalidade orientadora das intervenções, os procedimentos de monitoramento dos resultados e os critérios para interpretá-los. Os três ordenamentos em cascata serão tão consistentes quanto mais claramente compartilharem o mesmo paradigma - no caso da educação linguística, ensino behaviorista, inatista, interacionista. 
A terminalidade da educação linguística dentro de um currículo de Letras tanto mais permitirá e facilitará a formação de egressos profissionalmente preparados e competentes para o exercício de suas atribuições quanto mais clara e eficientemente apresentar ao estudante os paradigmas que ordenarão suas práticas. Cabe aos educadores linguísticos, além disso, empenharem-se na criação de associações que congreguem profissionais (seja da Academia, seja do mercado) pertencentes à mesma comunidade de práticas (em outras palavras, o mesmo paradigma) com o objetivo de cooperação e lealdade entre seus membros, visando à maior qualidade, dignidade e prestígio da profissão.

\section{REFERÊNCIAS BIBLIOGRÁFICAS}

ELIAS, N. Os estabelecidos e os outsiders. Rio de Janeiro: Jorge Zahar Editor, 2000.

ENGESTRÖM, Y. Learning by expanding: an activity-theoretical approach to developmental research. Helsinki, Orienta-Konsultit, 1987.

HALL, C.S.; GARDNER, L.; CAMPBELL, J.B. Teorias da personalidade. Porto Alegre: ARTMED, 2000.

LUHMANN, N. Sociologia do direito. Rio de Janeiro: Tempo Brasileiro, 1983, Vol. 1.

LUHMANN, N. Social systems. Stanford: Stanford University Press, 1995.

LUHMANN, N. Introdução à teoria dos sistemas. Petrópolis: Vozes, 2011.

PAIVA, V.L.M.O. O novo perfil dos cursos de licenciatura em Letras. In: TOMI$\mathrm{TCH}$, L. et al. (Orgs.) A interculturalidade no ensino de inglês. Florianópolis: UFSC, 2005, 345-363.

RICHTER, M. G. Aquisição, representação e atividade. Santa Maria: UFSM, PPGL Editores, 2008.

RICHTER, M. G. Profissionalização docente segundo a teoria holística da atividade: estudo empregando software de mapeamento semântico. In: Linguagem e interação: o ensino em pauta. São Carlos: Pedro \& João Editores, 2011.

STRACK, F.; DEUTSCH, R. Reflective and impulsive determinants of social behavior. In: Personality and Social Psychology Review, Vol. 8, № 3: 220-247, 2004.

VILLAS BOAS Fo, O. O direito na teoria dos sistemas de Niklas Luhmann. São Paulo: Max Limonad, 2006. 


\section{PEQUENO GLOSSÁRIO DE TEORIA HOLÍSTICA DA ATIVIDADE}

ACOPLAMENTO ESTRUTURAL - diz-se da justaposição operativa entre sistemas sigma, que pode resultar em: subserviência, cooperação, ou confrontação.

ALOPOIESE - Modo de funcionamento de um sistema, segundo o qual seus componentes e relações são reproduzidos em parte por operações internas ao sistema, quando tendem a ser regidas por expectativas cognitivas, e em parte por operações externas ao sistema (que Ihes dão suporte), quando tendem a ser regidas por expectativas normativas. Portanto é um sistema aloproduzido, alorregulado, alopreservado e alodesenvolvido. Quando em acoplamento com outros sistemas, é regulado em maior ou menor parte por eles.

AUTOPOIESE - Modo de funcionamento de um sistema, segundo o qual todos os seus componentes e relações são reproduzidos por operações internas ao próprio sistema, que tendem a ser regidas predominantemente por expectativas normativas. Portanto é um sistema autoproduzido, autorregulado, autopreservado e autodesenvolvido. Quando em acoplamento com outros sistemas, não é regulado por eles.

DESVIO AOS MEIOS - procedimento caracterizado por perda ou esvaziamento de finalismo quanto ao bem comum tacitamente acordado entre profissional e cliente e alvo de sua aliança e cooperação.

DISCURSO DO DÉFICIT - diz-se de formações discursivas alimentadas por observações sistêmicas centradas em juízos de valor pejorativos acerca de determinado papel social. Não confundir com pronunciamentos depreciativos sobre um ou outro indivíduo tomado isoladamente, dando a inferir exceções à regra. 
DUPLA CONTINGÊNCIA - é a condição irredutível e inerente a todo sistema sigma de operar a partir de expectativas postas diante de expectativas, de modo que nenhuma das partes pode operar exceto com base em eventos de produção de sentido probabilísticos.

ENDÓGENAS - diz-se de operações sistêmicas cuja origem é interna ao sistema.

EXÓGENAS - diz-se de operações sistêmicas cuja origem é externa ao sistema.

EXPECTATIVAS COGNITIVAS - no processo de redução de complexidade inerente ao funcionamento de um sistema, são expectativas resilientes aos fatos, de modo que eventos específicos têm o poder de desestabilizar padrões.

EXPECTATIVAS NORMATIVAS - no processo de redução de complexidade inerente ao funcionamento de um sistema, são expectativas resistentes aos fatos, de modo que eventos específicos, ou se integram a padrões estáveis, ou são "apagados" para as operações do referido sistema.

FATORES DE ATRIBUIÇÃO - são variáveis sistêmicas concernentes à constituição de determinado papel social nas suas esferas sistêmicas psi e sigma.

FATORES DE CONTROLE - são variáveis sistêmicas concernentes à emergência, manutenção e desenvolvimento de padrões de atividade relativos a determinado papel social.

FATORES DE MEDIAÇÃO - são variáveis sistêmicas concernentes à seleção e integração de padrões de atividade relativos a determinado papel social.

INTERPENETRAÇÃO - diz-se da justaposição operativa entre um sistema psi e um sistema sigma de modo que, por um lado, são entorno um para o outro e assim alimentam-se mutuamente de perturbações; e, de outro lado, realizam mútuas reduções de complexidade a priori, de modo a facilitar para ambos as operações internas de assimilação de perturbações.

SISTEMAS PSI - sistemas de produção de sentido constituídos de eventos cognitivo-afetivo-motores.

SISTEMAS SIGMA - sistemas de produção de sentido constituídos de eventos comunicativos. 